\title{
Alarms in a neurocritical care unit: a prospective study
}

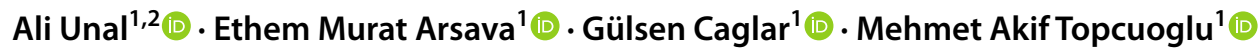

Received: 11 January 2021 / Accepted: 19 May 2021 / Published online: 27 May 2021

(c) The Author(s), under exclusive licence to Springer Nature B.V. 2021

\begin{abstract}
The contemporary practice of monitoring physiologic parameters in the critical care setting is based on alarm systems with high sensitivity but low specificity. A natural consequence of this approach is a massive amount of alarms, which potentially leads to fatigue in the personnel and negatively impacts the quality of care provided. The study objective is to determine the prevalence, types, and determinants of alarms in a neurological critical care unit (NCCU) prototype. During a one-month period corresponding to 272 days of monitoring in 34 patients, nursing staff recorded the type and number of sounding alarms in a university NCCU. Alarms were categorized into three types as type-A alarms that were merely handled by the nursing staff, type-B alarms that were primarily managed by nurses, but the physician was also notified, and type-C alarms that were principally handled by NCCU physicians. There were a total of 9439 alarms, with an average of daily 34.7 alarms per bed, corresponding to one alarm every $41.4 \mathrm{~min}$. Most of the alarms were type-A (57.7\%), followed by type-B (39.2\%) and type-C (3.1\%) alarms. Alarms originated from electrocardiogram (34.6\%), pulse oximeter (33.7\%), noninvasive blood pressure monitoring $(9.8 \%)$, respiratory monitoring $(9.7 \%)$, intravenous fluid pumps $(4.5 \%)$, ventilator (3.9\%), enteral pumps $(2.1 \%)$ and invasive blood pressure systems (1.7\%). A noticeable diurnal variation was observed for type-A pulse oximeter, type-A and -B ECG alarms (increase during morning shifts), and type-A ventilator alarms (decrease during morning shifts). Alarms are highly prevalent in NCCUs and can correspond to an important portion of the workload.
\end{abstract}

Keywords Neurointensive care $\cdot$ Alarm $\cdot$ False-negative $\cdot$ Prognosis $\cdot$ Specialty $\cdot$ Artificial intelligence $\cdot$ Alarm fatigue

\section{Introduction}

The long-standing paradigm of intensive care includes timely achievement and maintenance of normal physiology in critically ill patients in addition to administration of disease-specific treatment modalities. The mainstay of this approach is the efficient monitoring of physiological

Mehmet Akif Topcuoglu

mat@hacettepe.edu.tror; matopcuoglu@yahoo.com

Ali Unal

draliunal@gmail.com

Ethem Murat Arsava

arsavaem@hotmail.com

Gülsen Caglar

gulsenc.caglar@gmail.com

1 Faculty of Medicine, Neurology Department, Hacettepe University Hospitals, Neurointensive Care Unit, Sihhiye 06230, Ankara, Turkey

2 Neurology Department, Akdeniz University Hospitals, Antalya, Turkey parameters. Available monitoring strategies, using numbers for measuring physiological parameters and waveforms for assessing measurement quality, are currently based on alarm systems usually equipped with a high-pitched sound, which generally continue to beep unless silenced by human intervention. Reflecting the natural objectives of the monitoring mentality, alarms utilized by almost all of the monitoring techniques are highly sensitive but not that specific. The consequence is a multitude of continuously sounding alarms and high-level noise which makes the intensive care unit (ICU) unbearable for patients and care providers [1]. It is well established that high ambient noise disturbs the sleep quality of ICU patients, and disturbed sleep has a negative impact on prognosis via a number of mechanisms, including slower healing, impaired immune response, and decreased cognitive function [2]. Furthermore, nurses and other ICU personnel's continuous requirement of high-level alertness to alarm sounds, numbers, waveforms, etc. is quite exhaustive. Inevitably, this causes fatigue and desensitization to mostly rhythmic and monotonous alarm signals [3]. Monitor alarm fatigue, a newly recognized problem in critical 
care units, possibly increases with the number of parameters being monitored, and sometimes results in decreased responsiveness of care providers to physiologic aberrations. A high incidence of false alarms might also be a contributing factor to this phenomenon. The overall effect of monitor alarm fatigue on ICU prognosis is currently a matter of discussion $[4,5]$.

The significance of physiological alarms has been well studied in medical ICU's [6, 7]. However, different characteristics of the patients and environment may prevent direct applicability of these results to the neuroscience ICU's (abbreviated as "NCCU" for Neuro-Critical Care Unit). Therefore, there is an unmet need to perform specific studies to describe the prevalence and characteristics of alarms in regular NCCU's and validate their predictive and prognostic role in patient care. Our documentation can be considered the first effort in this regard. In addition, monitoring of specific cerebral parameters such as intracranial pressure (ICP), electroencephalographic activity, brain metabolism and oxygenation, and cerebral blood flow in addition to systemic parameters, albeit not explicitlytested in this study, undoubtedly increases the burden of alarms in advanced NCCU's.

In this study, we studied the intensity of patient monitoring alarms and how they were resolved in a standard NCCU, by using a new alarm categorization to evaluate the worksharing in the management of alarms.

\section{Methods and patients}

This prospective study was performed in a nine-bed NCCU setting at Hacettepe University Hospitals, Turkey. The unit is run in three shifts; the day-time team consists of two neurointensivists, two residents, 14 nurses, six nurse assistants, and one visiting neuro-intensivist. Evening and night shift teams consist of one senior resident, three nurses, three nurse assistants, and one on-call neuro-intensivist. For this study, we collected data consecutively from a total of 34 patients that were admitted during one month, which in total corresponded to 272 days of monitoring (bed occupancy rate $97 \%$ ).

\subsection{Patients' characteristics}

There were 18 female [mean \pm standard deviation, "SD": age: $65 \pm 18$ years] and 16 male (mean \pm SD age: $64 \pm 11$ years) patients in the study. Twenty-six (77\%) patients were admitted to the NCCU because of acute and/ or complicated neurovascular disease: massive intracerebral hemorrhage in eight, large middle cerebral artery/internal carotid artery infarction in five, post-thrombolysis observation in four, vertebrobasilar stroke with impaired consciousness in three, post-procedural hyperperfusion syndrome in two, space-occupying cerebellar infarction that later necessitated posterior decompression in one, dural sinus thrombosis in one, intra-infarct hematoma complicated by pulmonary thromboembolism in one and anterior cerebral artery infarction complicated by pneumonia in one. The other admission diagnoses included status epilepticus in three, meningoencephalitis/encephalitis in two, Guillain-Barré syndrome in two and myasthenic crisis in one patient.

The average daily Simplified Acute Physiology Score II (SAPS II) [8] was 27.9 \pm 12.1 (range: 6 to 78 ) and SAPSII based predicted mortality rate was $13 \pm 17 \%$ (range: 0.5 to $91.4 \%$ ). The mean \pm SD of Glasgow coma scale (GCS) total score was $12.2 \pm 3.4$ (19.7\% between 3 and $8 ; 27.4 \%$ between 9 and 13; and 52.7\% between 14 and 15).

Excluding three patients who died, the mean \pm SD modified Rankin score [9] at the time of NCCU and hospital discharge were $4.03 \pm 1.08$ and $3.0 \pm 1.39$, respectively. The modified Rankin score was less than three in nine (29\%) patients and less than four in $19(61 \%)$ patients at the time of hospital discharge.

\subsection{Monitoring settings}

Altogether, 272 days of monitoring were evaluated. The mean \pm SD time of monitoring per patient was $8 \pm 6.9$ days (median 6, range: 1 to 29). In all patients, oxygen saturation, electrocardiogram (heart rate and rhythm), respiratory rate and rhythm, and noninvasive systolic/diastolic blood pressure (NIBP) were monitored with Philips IntelliVue ${ }^{\circledR}$ MP20 system. The same system was used for invasive blood pressure (IBP) monitoring on 44 (16\%) days. In addition to bedside monitors, all these parameters could be monitored by two central stations (Philips IntelliVue Information Center() located in the nursing desk and physician room at the unit, which enabled remotely turning off the alarms without going to the bedside. At least one intravenous infusion pump (Abbott Plum-A® IV infusion set) was used on all days. Enteral feeding via nasogastric, orogastric or jejunal tube was performed by an enteral nutrition infusion pump (Abbott Kangaroo ${ }^{\circledR} 624$ enteral feeding pump) on $210(77 \%)$ days. Invasive mechanical ventilation was present on 120 (44\%) days; mechanical ventilators used were Maquet servo $i \circledR$ with main-stream capnography (87 days) and Engström carestation ${ }^{\circledR}$ with side-stream capnography (33 days). No patient necessitated noninvasive mechanical ventilation during the study period. Oxygen supplementation was utilized on 266 (98\%) days. End-tidal $\mathrm{PCO}_{2}$ monitoring without mechanical ventilation was performed on only four days and therefore was not analyzed further. Albeit used during the study period and available in the unit, alarms from video-electroencephalography and ICP monitoring were not analyzed due to their low frequency of usage. 


\subsection{Definition of alarms}

Alarms were classified into three categories according to how and by whom they were dealt with:

Type-A alarms were alarms cleared by simple nursing measures and were perceived by the nurses as not significant enough to notify the physicians. These were mostly technical or patient-induced alarms. Examples of technical alarms include detachment of oxygen saturation probes or electrocardiogram (ECG) electrodes. Examples of induced alarms are enteral or intravenous infusion pump failures due to folding or blockage of the tubing set because of the movement of the patient. It is important to note that this category of alarms is not simple in every incidence and may be secondary to very critical situations such as disruption of the ventilator circuit integrity.

Type-B alarms were alarms in which the physicians were informed by the nursing staff but were considered benign so that no further diagnostic evaluations were carried on. Examples include readings outside the thresholds set for heart rate, blood pressure, oxygen saturation or mechanical ventilation parameters. These alarms necessitated no therapeutic interventions at all or were handled by simple measures such as increasing the $\mathrm{FiO}_{2}$ by introducing an oronasal mask instead of a nasal cannula or reestablishing the limits of the alarm parameters.

Type-C alarms were alarms that were considered serious, requiring diagnostic and therapeutic interventions primarily by the physicians. Examples are ECG, pulse oximetry or capnometry changes necessitating immediate therapeutic interventions or new diagnostic tests such as cardiac enzymes or arterial blood gas analyses.

As a general example, infrequent premature supraventricular or ventricular beats, irregular heart rate due to known atrial fibrillation, low-degree tachycardia and bradycardia are type-A alarms; hemodynamically insignificant short-duration atrial tachycardia, medium-degree tachycardia and bradycardia are type-B alarms; and finally extreme high or low heart rate or serious ventricular arrhythmias are type-C alarms.

The nurses marked all alarms in the pre-prepared forms according to the classification mentioned above. The forms were then reviewed daily by the investigators to avoid misclassifications. Alarms automatically recorded on the devices were not taken into consideration. Unless a patient required a specific adjustment, universal limits were used in the alarm initiation settings. It is important to note that two types of alarms were not included in this study. The first is "anticipated induced alarms", which are the alarms originating from manipulation of the patient or monitoring system by staff such as encountered during suctioning or repositioning. The second is "initialization alarms", which are the alarms occurring during a certain period until the device or system is optimized after switched on or reconnected.

\subsection{Statistical analysis}

All numerical values are given as mean $\pm \mathrm{SD}$, median $\pm \mathrm{IQR}$ (Interquartile range), and percent as appropriate. Distribution normality was determined by Kolmogorov-Smirnov and Shapiro-Wilk tests as appropriate. Students' t, pairedt, Mann-Whitney U, chi-square and exact tests were used appropriately according to the numerical/categorical or paired/independent character of the data. Correlation analysis was performed with the Pearson test. The Pearson correlation coefficient (r) between 1 and 0.8 was categorized as "very strong", 0.6 to 0.8 as "strong", 0.6 to 0.4 as "moderate", 0.4-0.2 as "weak" and less than 0.2 as "negligible (or very weak)".Diurnal variation of the variables was tested with analysis of variance for repeated measures. In this hourbased 24-h long analysis, the Greenhouse-Geisser method was used appropriately for testing within-subjects effects and the Bonferroni method for adjustment of confidence intervals for multiple comparisons. The significance level for the $\mathrm{p}$ value in correlation analysis was accepted as 0.012 after Bonferroni correction. In other evaluations, $p$ value lower than 0.05 was set as the statistical significance level. SPSS ${ }^{\circledR} 22.0$ statistical package-program (IBM SPSS Statistics for Windows, IBM Corp., Armonk, NY) was used for the analyses.

\section{Results}

In total, 9439 alarms corresponding to an average of 34.7 alarms per day and 1.45 alarms per hour for every bed were noted by the nursing team during the study period. The majority of alarms were type-A $(n=5446,57.7 \%)$ and type$\mathrm{B}(\mathrm{n}=3700,39.2 \%)$. Type-C alarms were present on only 293 (3.1\%) occasions (1.07 per day).

Out of the 9439 alarms, 3,183 (33.7\%) were related to monitoring oxygen saturation. This corresponded to an average of 11.7 alarms per day (Table 1). At least one alarm was noted on 248 (90.8\%) monitoring days. Of these, $2.5 \%$ were considered type-C and noted on 15 (5.5\%) days. A low-grade negative correlation was noted between SAPS-II scores and type-A and -B alarms but not with type-C ones (Table 2). SAPS-II scores were higher on days without saturation alarms $(33.5 \pm 15.3$ vs. $27.3 \pm 11.6, p=0.014)$. No correlation with GCS (total and its sub-items) and saturation alarms were noted (Table 2). Type-A saturation alarms showed a significant diurnal variation (Fig. 1a), indicating an increase during the first half of the morning shift (between 9:00 and 12:00) and a decrease in the early morning (between 04:00 and 07:00) $(\mathrm{F}=5.198, \mathrm{p}<0.001)$. 
Table 1 Alarm frequencies

\begin{tabular}{|c|c|c|c|c|}
\hline Type of alarm & Type-A & Type-B & Type-C & Total \\
\hline \multicolumn{5}{|l|}{ Saturation } \\
\hline $\mathrm{n}$ & 1758 & 1347 & 78 & 3183 \\
\hline $\begin{array}{l}\text { Daily average per } \\
\text { bed }\end{array}$ & $6.4 \pm 6.7$ & $4.9 \pm 11.0$ & $0.29 \pm 1.57$ & $11.7 \pm 13.9$ \\
\hline Median(IQR) & $5(0-31)$ & $0(0-83)$ & $0(0-13)$ & $8(0-85)$ \\
\hline \multicolumn{5}{|l|}{ ECG } \\
\hline $\mathrm{n}$ & 2096 & 1139 & 31 & 3266 \\
\hline $\begin{array}{l}\text { Daily average per } \\
\text { bed }\end{array}$ & $7.7 \pm 8.5$ & $4.17 \pm 10.6$ & $0.11 \pm 0.84$ & $12.0 \pm 13.9$ \\
\hline Median(IQR) & $6(0-66)$ & $0(0-90)$ & $0(0-11)$ & $8(0-99)$ \\
\hline \multicolumn{5}{|l|}{ NIBP } \\
\hline $\mathrm{n}$ & 172 & 675 & 72 & 921 \\
\hline $\begin{array}{l}\text { Daily average per } \\
\text { bed }\end{array}$ & $0.6 \pm 2.1$ & $2.4 \pm 7.4$ & $0.3 \pm 1.5$ & $3.4 \pm 7.8$ \\
\hline Median(IQR) & $0(0-20)$ & $0(0-55)$ & $0(0-16)$ & $0(0-66)$ \\
\hline \multicolumn{5}{|l|}{ RR } \\
\hline $\mathrm{n}$ & 670 & 238 & 6 & 914 \\
\hline $\begin{array}{l}\text { Daily average per } \\
\text { bed }\end{array}$ & $2.5 \pm 5.1$ & $0.9 \pm 2.7$ & $0.02 \pm 0.25$ & $3.35 \pm 5.71$ \\
\hline Median (IQR) & $0(0-31)$ & $0(0-17)$ & $0(0-4)$ & $0(0-31)$ \\
\hline \multicolumn{5}{|l|}{ IV pump } \\
\hline $\mathrm{n}$ & 420 & 2 & 2 & 424 \\
\hline $\begin{array}{l}\text { Daily average per } \\
\text { bed }\end{array}$ & $1.5 \pm 3.2$ & - & - & $3.16 \pm 10.0$ \\
\hline Median(IQR) & $0(0-19)$ & 0 and 2 & 0 and 1 & $0(0-19)$ \\
\hline \multicolumn{5}{|l|}{ Enteral pump* } \\
\hline $\mathrm{n}$ & 197 & 2 & 1 & 200 \\
\hline $\begin{array}{l}\text { Daily average per } \\
\text { bed }\end{array}$ & $0.94 \pm 1.8$ & - & - & $0.95 \pm 1.78$ \\
\hline Median(IQR) & $0(0-9)$ & 0 and 2 & 1 & $0(0-9)$ \\
\hline \multicolumn{5}{|l|}{ Ventilator* } \\
\hline $\mathrm{n}$ & 94 & 239 & 36 & 369 \\
\hline $\begin{array}{l}\text { Daily average per } \\
\text { bed }\end{array}$ & $0.8 \pm 2.3$ & $2.0 \pm 5.4$ & $0.3 \pm 2.1$ & $3.1 \pm 6.7$ \\
\hline Median(IQR) & $0(0-12)$ & $0(0-36)$ & $0(0-18)$ & $0(0-36)$ \\
\hline \multicolumn{5}{|l|}{ IBP* } \\
\hline $\mathrm{n}$ & 37 & 58 & 67 & 162 \\
\hline $\begin{array}{l}\text { Daily average per } \\
\text { bed }\end{array}$ & $0.14 \pm 1.5$ & $0.21 \pm 1.5$ & $0.25 \pm 3.0$ & $0.59 \pm 4.1$ \\
\hline Median(IQR) & $0(0-23)$ & $0(0-18)$ & $0(0-48)$ & $0(0-51)$ \\
\hline
\end{tabular}

$I B P$ invasive blood pressure, $I Q R$ inter quartile range, $I V$ intravenous, $N I B P$ non-invasive blood pressure, $R R$ respiratory rate. ${ }^{*} \mathrm{n}=210$ for enteral pump; $n=120$ for ventilator usage; $n=44$ for IBP

The total number of ECG alarms was 3266 (34.6\% of total) with a daily mean of 12.0 (Table 1). At least one ECG alarm was recorded on 241 (88.6\%) days. Type-C alarms constituted $0.9 \%$ of all ECG alarms and were present on $11(4 \%)$ days. There was no significant correlation between ECG alarm types and SAPS-II score (Table 2). No difference was noted on days with and without ECG alarms in terms
Table 2 Correlation between alarm numbers and SAPS-II and GCS

\begin{tabular}{|c|c|c|c|c|c|}
\hline \multirow[t]{2}{*}{ Monitoring modality } & \multirow[t]{2}{*}{ Type } & \multicolumn{2}{|l|}{ SAPS-II } & \multicolumn{2}{|c|}{ GCS-total } \\
\hline & & $\mathrm{r}$ & $\mathrm{p}$ & $\mathrm{r}$ & $\mathrm{p}$ \\
\hline \multirow[t]{4}{*}{ Oxygen saturation } & A & -0.201 & $0.001 *$ & 0.135 & 0.025 \\
\hline & $\mathrm{B}$ & -0.128 & 0.034 & 0.032 & 0.601 \\
\hline & $\mathrm{C}$ & -0.027 & 0.656 & -0.059 & 0.331 \\
\hline & Total & -0.202 & $0.001 *$ & 0.084 & 0.167 \\
\hline \multirow[t]{4}{*}{ Electrocardiogram } & $\mathrm{A}$ & -0.030 & 0.621 & 0.092 & 0.130 \\
\hline & $\mathrm{B}$ & 0.089 & 0.145 & -0.054 & 0.337 \\
\hline & $\mathrm{C}$ & 0.122 & 0.064 & -0.134 & 0.027 \\
\hline & Total & 0.055 & 0.361 & 0.017 & 0.907 \\
\hline \multirow{4}{*}{$\begin{array}{l}\text { Non-invasive blood } \\
\text { pressure }\end{array}$} & A & -0.206 & $0.001 *$ & 0.100 & 0.098 \\
\hline & $\mathrm{B}$ & 0.022 & 0.719 & 0.107 & 0.076 \\
\hline & $\mathrm{C}$ & 0.065 & 0.286 & 0.067 & 0.267 \\
\hline & Total & -0.021 & 0.735 & 0.140 & 0.020 \\
\hline \multirow[t]{4}{*}{ Respiratory } & A & -0.107 & 0.079 & -0.005 & 0.930 \\
\hline & $\mathrm{B}$ & -0.097 & 0.109 & 0.115 & 0.058 \\
\hline & $\mathrm{C}$ & -0.084 & 0.165 & 0.067 & 0.270 \\
\hline & Total & -0.145 & $0.016^{*}$ & 0.053 & 0.384 \\
\hline \multirow{4}{*}{$\begin{array}{l}\text { Intravenous infusion } \\
\text { pumps }\end{array}$} & A & -0.093 & 0.127 & 0.043 & 0.477 \\
\hline & $\mathrm{B}$ & -0.034 & 0.571 & 0.033 & 0.592 \\
\hline & $\mathrm{C}$ & -0.024 & 0.694 & -0.104 & 0.088 \\
\hline & Total & -0.094 & 0.120 & 0.042 & 0.494 \\
\hline \multirow[t]{4}{*}{ Enteral infusion pump } & A & 0.193 & $0.001 *$ & -0.116 & 0.055 \\
\hline & $\mathrm{B}$ & -0.075 & 0.220 & 0.015 & 0.806 \\
\hline & $\mathrm{C}$ & 0.046 & 0.452 & -0.073 & 0.229 \\
\hline & Total & 0.189 & $0.002 *$ & -0.118 & 0.052 \\
\hline \multirow[t]{4}{*}{ Ventilator } & A & 0.260 & $0.001 *$ & -0.184 & $0.002 *$ \\
\hline & $\mathrm{B}$ & 0.241 & $0.001 *$ & -0.176 & $0.003 *$ \\
\hline & $\mathrm{C}$ & 0.204 & $0.001 *$ & -0.185 & $0.002 *$ \\
\hline & Total & 0.331 & $0.001 *$ & -0.250 & $0.001 *$ \\
\hline \multirow[t]{4}{*}{ Invasive blood pressure } & $\mathrm{A}$ & 0.233 & $0.001 *$ & -0.164 & $0.007 *$ \\
\hline & $\mathrm{B}$ & 0.144 & $0.017 *$ & -0.148 & $0.015^{*}$ \\
\hline & $\mathrm{C}$ & 0.208 & $0.001 *$ & -0.201 & $0.001 *$ \\
\hline & Total & 0.288 & $0.001 *$ & -0.260 & $0.001 *$ \\
\hline
\end{tabular}

*Significance level was set at $\mathrm{p}=0.012$ as per Bonferroni's correction

of the average SAPS-II scores $(25.9 \pm 15.5$ vs. $28.1 \pm 11.6$, $\mathrm{p}=0.322$ ). There was no correlation between ECG alarms and GCS scores (Table 2). Type-A ECG alarms again increased during the first half of the morning shift (between 9:00 and 12:00), while a decrease of both type-A and -B alarms were noted in the early morning (between 04:00 and 07:00) (Fig. 1b) $(\mathrm{F}=6.543, \mathrm{p}<0.001$ for type-A ECG alarms; $\mathrm{F}=2.391, \mathrm{p}=0.013$ for type-B ECG alarms).

In sum, 921 NIBP alarms ( $9.8 \%$ of all alarms) were noted. The average daily NIBP alarm number was 3.4 (Table 1). There was at least one NIBP alarm on $123(45 \%)$ monitoring days. Type-C NIBP alarms generated $7.8 \%$ of these kinds of alarms and were noted on 17 (6.2\%) days. A negative correlationtrend was noted between the SAPS-II score and type-A 


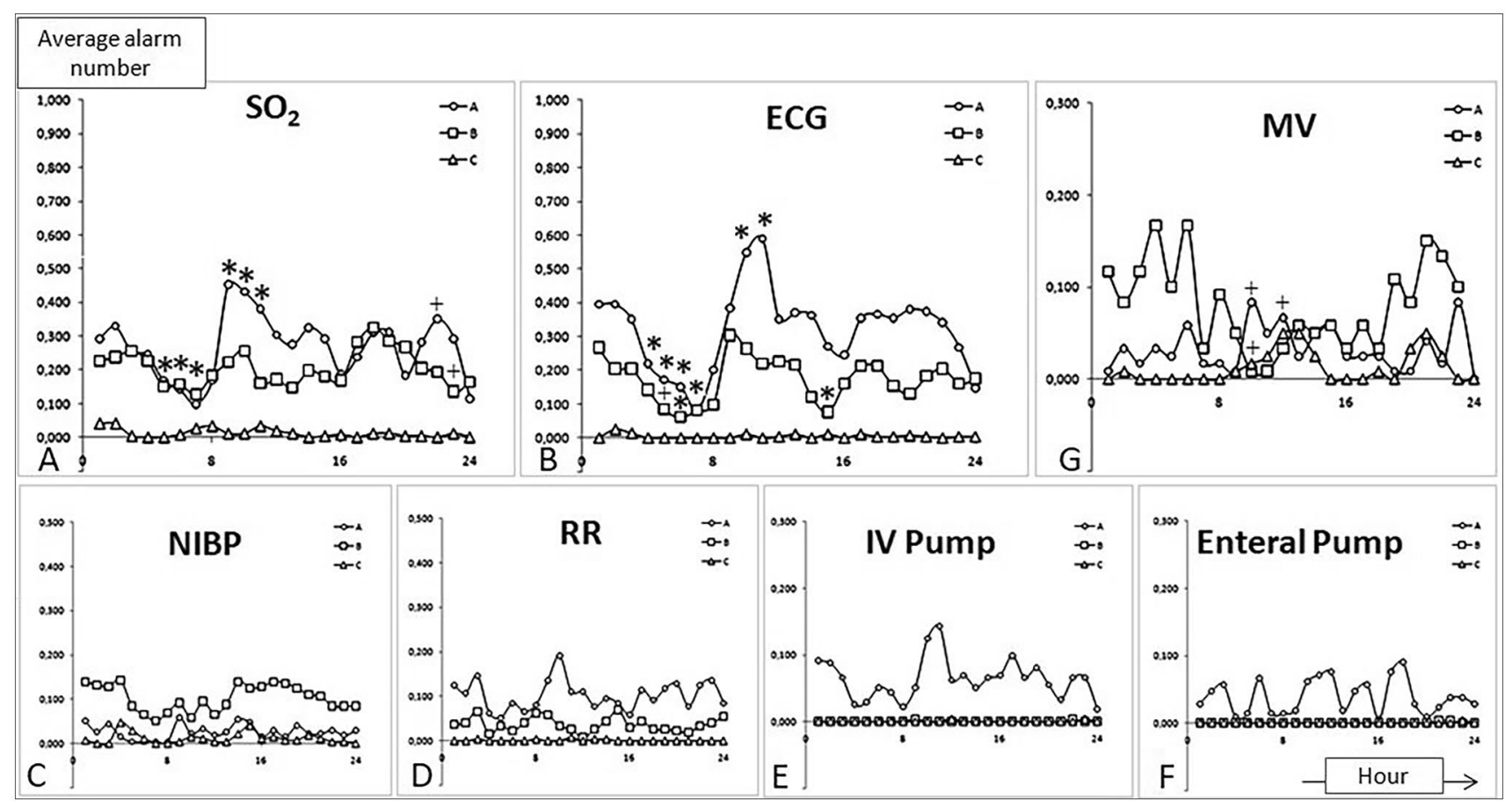

Fig. 1 Diurnal variation of alarm subtypes. $E C G$ electrocardiogram, $I B P$ invasive blood pressure, $I V$ intravenous, $M V$ mechanical ventilation, $N I B P$ non-invasive blood pressure, $R R$ respiratory rate, $S O_{2}$ oxygen saturation. ${ }^{*} \mathrm{p}<0.05$ (significant), ${ }^{+} \mathrm{p}<0.1$ (trend)

NIBP alarms but not with type-B and C ones (Table 2). SAPS-II scores were not different on days with and without NIBP alarms $(31.5 \pm 10.9$ vs. $27.6 \pm 12.1, \mathrm{p}=0.199)$. NIBP alarms were not correlated with GCS scores (Table 2). NIBP alarms did not show a significant diurnal variation (Fig. 1c).

There were 914 respiratory rate (RR) alarms $(9.7 \%$ of all alarms) with an average of 3.4 per day (Table 1). There was at least one RR alarm on 125 (46\%) monitoring days. Type-C RR alarms comprised $0.7 \%$ of these kinds of alarms and were noted on $3(1.1 \%)$ days. A weak but still significant negative correlation was noted between the SAPS-II score and total RR alarm number $(\mathrm{p}=0.016)$; however, this correlation did not reach statistical significance when analyzed separately for alarm subgroups (Table 2). SAPS-II scores were significantly less on days without $\mathrm{RR}$ alarms compared to those without $(24.7 \pm 8.4$ vs. $30.5 \pm 14.0 ; \mathrm{p}<0.001)$. No correlation was observed between RR alarms and GCS scores (Table 2). RR alarms did not show a significant diurnal variation (Fig. 1d).

There were a total of 424 (4.5\%) alarms originating from intravenous infusion pumps. These types of alarms were noted with an average of 3.1 per day (Table 1). There was at least one intravenous pump alarm on $108(40 \%)$ monitoring days. Type-C intravenous pump alarms were noted on only two occasions. No significant correlation was evident between the SAPS-II score and intravenous pump alarm incidence (Table 2). SAPS-II scores were not significantly different on days with alarms in comparison with those without $(27.6 \pm 10.3$ vs. $28.1 \pm 13.2 ; p=0.782)$. Infusion pump alarms were not correlated with the GCS score and did not show a significant diurnal variation (Table 2 and Fig. 1e).

There were $200(2.1 \%)$ alarms caused by enteral infusion pumps. These type alarms were noted at an average of 0.94per day used (Table 1). There was at least one enteral pump alarm on 74 (35\%) monitoring days. Type-C alarm was noted on only one occasion. A significant but marginal correlation was noted between the SAPS-II score and type-A enteral pump alarm number (Table 2). SAPS-II scores were not different on days with alarms compared to those without $(31.9 \pm 11.9$ vs. $29.2 \pm 13.2 ; p=0.141)$. No correlation was noted between enteral infusion pump alarms and GCS scores (Table 2). Enteral infusion pump alarms did not show a significant diurnal variation (Fig. 1f).

Mechanical ventilators were used on 120 (44\%) days. The average SAPS-II score was significantly higher in these days compared to those during which mechanical ventilators were not used $(40.0 \pm 13.3$ vs. $21.5 \pm 5.7, p<0.001)$. Ventilator alarms were noted on an average of 3.1per day (Table 1). Nurses informed physicians on at least one alarm on 44 (37\%) of the days' mechanical ventilation was used. A type-C alarm was noted in $36(9.8 \%)$ of the occasions. Ventilator alarms were positively correlated with SAPS-II ( $\mathrm{r}$ values between 0.204 and 0.331 ) and negatively ( $\mathrm{r}$ values between -0.118 and -0.185 ) with GCS (Table 2). SAPS-II 
scores were significantly higher on ventilator days than those without $(41.3 \pm 14.7$ vs. $32.9 \pm 11.4 ; \mathrm{p}=0.001)$. A-type ventilator alarms showed a nonsignificant trend to decrease during late morning shifts (Fig. 1g).

Invasive blood pressure (IPB) monitoring was used on 44 (16\%) days. Out of 162 alarms noted, 37 were type-A, 58 were type-B, and 67 were type-C. At least one alarm was noted in $13(30 \%)$ days out of all days IBP monitoring was performed. Invasive blood pressure alarms were also positively correlated with SAPS-II and negatively correlated with GCS. This was weakly significant ( $\mathrm{r}$ value varied between 0.144 and 0.288 for SAPS-II, and -0.164 to -0.260 for GCS) or simply indicated the presence of trend (For type-B alarm) (Table 2). SAPS-II score was slightly higher on days when IBP monitoring was done $(31.7 \pm 17.5$ vs. $27.1 \pm 10.7 ; p=0.023)$. No diurnal variation was noted (Data not shown).

\section{Discussion}

Our study indicates that the frequency of physiological alarms occurring in NCCUs' is comparable to those in medical ICU's. In a multicenter study of monitoring alarms held in five adult medical ICU's, an average of one alarm was recorded every $37 \mathrm{~min}$ [6]. In our cohort, we detected one alarm every $41.4 \mathrm{~min}$ on average for a bed. As we excluded "anticipated induced alarms" and "initialization alarms", the frequency might be slightly higher than medical ICU's, considering that at least one-quarter of the alarms were due to staff manipulation in the mentioned study [6]. Besides, more frequent use of cerebral monitoring tools and frequent transfer of patients to radiology suits may further increase alarm frequency in other NCCU's which routinely admit neurotrauma patients in contrast to ours.

Because each alarm should be checked promptly at the bedside, their high frequency adds a lot to the workload of ICU nurses who are in the first position to respond to an alarm. According to most ICU policies, determining the importance of alarms and deciding which alarms are critical is under their responsibility. In our study, on approximately $60 \%$ of occasions, the nurses solved the problems by themselves without notifying the physicians. On the other hand, physicians were called to the bedside in $40 \%$ of alarms, of which only one in 10 occasions was critical enough to require diagnostic or major therapeutic intervention. In other words, nurses handled an alarm every 41 min (312 times a day in our nine-bed unit) on average, while senior physicians go to the bedside for this reason just 1.07 times (9.6 times in our nine-bed unit) per day. This number is slightly less but still comparable to the frequency published for medical ICU's [7]; for example, compared to $3.1 \%$ in our study, the incidence of type-C alarms was $5.9 \%$ in the aforementioned multicenter study [6]. It is important to note that this alarm classification scheme does not indicate a grade of priority and importance but merely categorizes the use of human resources in terms of workload needed for taking care of the alarms. For example, a type-A alarm such as ventilator circuit disconnection is a high-priority alarm indicating an urgent situation that requires immediate attention; in contrast a type-C alarm such as an inspiratory peak pressure threshold alarm in a ventilated patient may not be that important. Therefore, we cannot classify alarms as false and true or relevant and irrelevant from the perspective of clinical vitality based on our data.

We detected a relationship between alarm type and the involvement of the treating physician. Similar to the previous studies performed in other subspecialty ICU's [7, 10, $11]$, the vast majority of the alarms occurring in NCCU originate from saturation and ECG monitoring [ $68.3 \%$ of all alarms, corresponding to almost one alarm per hour $(0.988)$ for a bed]. The attending physicians were actively involved in only $3.4 \%$ of these incidences. In terms of alarms originating from respiratory rate, infusion pumps, and enteral pumps, the senior physicians' involvement is in the range of $1 \%$. On the other hand, physician involvement was higher in NIBP and ventilator alarms (7.8\% and 9.8\%, respectively). Although the reason was primarily technical, physicians were directly involved in a significant portion $(41.4 \%)$ of alarms related to invasive arterial blood pressure measurement. As the correlation with SAPS-II and GCS scores are marginal or absent, it would not be wrong to state that this increased frequency of physicians' involvement with ventilator and invasive monitoring might be related to relative under-confidence or inexperience of nurses with these devices and their techniques, rather than the severity of the clinical status.

While no diurnal variation was recorded for invasive and noninvasive blood pressure, respiratory rate, enteral and parenteral pump alarms, we detected a significant, albeit weak, diurnal variation in type-A saturation and ECG alarms (decreases during early morning but increases during late in the morning). Although not specifically analyzed in this study, this might reflect the sleep-wakefulness cycle of patients, with more alarms observed during early hours of awakening and relative nursing personnel surplus. On the other hand, we observed relatively more ventilator alarms during evening and night shifts which cannot be explained in the same way and seemingly is also not related to the attitude of the nursing staff because there was no increase in invasive blood pressure alarms during the same periods.

The frequency and types of alarm signals and the underlying causes are not significantly different between NCCU's and other subspecialty ICU's, in terms of alarms related to cardiovascular and respiratory monitoring, and those originating from ventilators and intravenous or enteral perfusion. 
Albeit cerebral monitoring alarms further complicate the situation in NCCU's, other specific monitoring tools are also available in other ICU's such as those associated with aortic balloon pumps in the coronary care units. Therefore, any strategy developed for alarm reduction could be applicable widely regardless of ICU type. Optimizing alarm settings at regular intervals or after any change in clinical status is a significant part of the workload of caregivers in the NCCUs. The increased workload and high-level nuisance seem to be a significant problem with negative consequences beyond discussion. However, we cannot say that a reasonable solution for this problem has been found [12]. Expansion of the number of the nursing team is usually suggested but is not economically feasible. Continuous education, flexible nursing policy, and ergonomic unit design, along with better sensor and measurement technology, were not successful in reducing the number of alarms $[13,14]$. Similar to automatic pilot technology introduced for aircraft, a technological system taking human and human-related errors beyond the central point may be of pivotal importance. However, available signal analysis and data management algorithms for alarm generation, grading, and discrimination of significant events from false ones are currently in their infancy in this respect [15]. A system automatically recognizing "anticipated induced" and "initialization" alarms such as those occurring during suctioning, mobilization, and cleaning to reduce the total number of alarms is considered a good step in the right direction [7]. However, even if this goal is achieved, the burden associated with alarms will still be significant, as demonstrated in our study, where such alarms were excluded.

Authors' contribution Ready to send upon request.

Funding None.

Data availability Available upon reasonable request.

\section{Declarations}

Conflict of interest The authors declare that they have no conflict of interest.

Ethical approval The protocol was approved HUTF non-interventional ethical committee.

Consent for publication Approved.
2. Lawson N, Thompson K, Saunders G, Saiz J, Richardson J, Brown D, Ince N, Caldwell M, Pope D.Sound intensity and noise evaluation in a critical care unit. Am J Crit Care. 2010;19(6):e88-98; quiz e99. https://doi.org/10.4037/ajcc2010180.

3. Graham KC, Cvach M. Monitor alarm fatigue: standardizing use of physiological monitors and decreasing nuisance alarms. Am J Crit Care. 2010;19(1):28-34;quiz 35. https://doi.org/10.4037/ ajcc2010651.

4. Wilken M, Huske-Kraus D, Rohrig R. Alarm fatigue: using alarm data from a patient data monitoring system on an intensive care unit to improve the alarm management. Stud Health Technol Inform. 2019;267:273-81. https://doi.org/10.3233/SHTI190838.

5. Wung SF, Schatz MR. Critical care nurses' cognitive ergonomics related to medical device alarms. Crit Care Nurs Clin North Am. 2018;30(2):191-202. https://doi.org/10.1016/j.cnc.2018.02.002.

6. Chambrin MC, Ravaux P, Calvelo-Aros D, Jaborska A, Chopin C, Boniface B. Multicentric study of monitoring alarms in the adult intensive care unit (ICU): a descriptive analysis. Intensive Care Med. 1999;25(12):1360-6. https://doi.org/10.1007/s001340051 082.

7. Siebig S, Kuhls S, Imhoff M, Gather U, Scholmerich J, Wrede CE. Intensive care unit alarms-how many do we need? Crit Care Med. 2010;38(2):451-6. https://doi.org/10.1097/CCM.0b013 e3181cb0888.

8. Le Gall JR, Lemeshow S, Saulnier F. A new Simplified Acute Physiology Score (SAPS II) based on a European/North American multicenter study. JAMA. 1993;270(24):2957-63.

9. Rankin J. Cerebral vascular accidents in patients over the age of 60 II. Prognosis Scott Med J. 1957;2(5):200-15.

10. Tsien CL, Fackler JC. Poor prognosis for existing monitors in the intensive care unit. Crit Care Med. 1997;25(4):614-9.

11. Korniewicz DM, Clark T, David Y. A national online survey on the effectiveness of clinical alarms. Am J Crit Care. 2008;17(1):36-41.

12. Curry JP, Jungquist CR. A critical assessment of monitoring practices, patient deterioration, and alarm fatigue on inpatient wards: a review. Patient Saf Surg. 2014;8:29. https://doi.org/10.1186/ 1754-9493-8-29.

13. Richards NM, Giuliano KK, Jones PG. A prospective comparison of 3 new-generation pulse oximetry devices during ambulation after open heart surgery. Respir Care. 2006;51(1):29-35.

14. Brantley A, Collins-Brown S, Kirkland J, Knapp M, Pressley J, Higgins M, McMurtry JP. Clinical trial of an educational program to decrease monitor alarms in a medical intensive care unit. AACN Adv Crit Care. 2016;27(3):283-9. https://doi.org/10.4037/ aacnacc2016110.

15. Muroi C, Meier S, De Luca V, Mack DJ, Strassle C, Schwab P, Karlen W, Keller E. Automated false alarm reduction in a reallife intensive care setting using motion detection. Neurocrit Care. 2020;32(2):419-26. https://doi.org/10.1007/s12028-019-00711-w.

Publisher's Note Springer Nature remains neutral with regard to jurisdictional claims in published maps and institutional affiliations.

\section{References}

1. Phillips J. Clinical alarms: complexity and common sense. Crit Care Nurs Clin North Am. 2006;18(2):145-56. https://doi.org/10. 1016/j.ccell.2006.01.002. 